\title{
Analisis Asam Lemak Omega 3 dan 6 pada Minyak Ikan Lele secara GC- FID
}

\author{
Analysis of omega 3 and 6 fatty acids in catfish oil by GC-FID
}

\author{
Maruba Pandiangan',2,*, Jamaran Kaban ${ }^{3}$, Basuki Wirjosentono ${ }^{3}$ and Jansen Silalahi ${ }^{4}$ \\ ${ }^{1}$ Program Pascasarjana Doktor Ilmu Kimia, Universitas Sumatera Utara, Medan \\ ${ }^{2}$ Prodi Teknologi Hasil Pertanian, Universitas Katolik Santo Thomas, Medan \\ ${ }^{3}$ Departemen Kimia FMIPA, Universitas Sumatera Utara, Medan \\ ${ }^{4}$ Fakultas Farmasi, Universitas Sumatera Utara, Medan \\ *email: maruba.pandiangan@gmail.com
}

\begin{abstract}
Omega 3 and 6 fatty acids are very good consumed to improve human health. For this reason, research is needed to determine the glyceride profile and identification of omega 3 and 6 fatty acids in fat molecules so that the potential of catfish oil as a source of omega 3 and 6 can be known. Catfish oil was extracted by the soxletation method. Fatty acid composition was analyzed by gas chromatography (GC-FID) which was previously esterified using BF3. The results showed that the composition of unsaturated fatty acids more than saturated fatty acids. Omega-3 fatty acids are found consisting of linolenic acid, eicosapentanoic acid (EPA) and docosahexanoic acid (DHA) and omega 6, namely linoleic acid. The comparison of omega 3 and omega 6 in catfish oil is still within the recommended comparison terms. Judging from the composition and position of catfish oil fatty acids which contain omega 3 and omega 6 fatty acids. Thus catfish oil has the potential as a source of omega 3 and 6 from one of the freshwater fish that are consumed by many people.
\end{abstract}

Keywords: fatty acids, omega 3 and 6, catfish, esterification, GC-FID

\begin{abstract}
ABSTRAK
Asam lemak omega 3 dan 6 sangat baik dikonsumsi untuk meningkatkan kesehatan manusia.. Untuk itu perlu dilakukan penelitian untuk mengetahui profil gliserida dan identifikasi asam lemak omega 3 dan 6 dalam molekul lemak sehingga potensi minyak ikan lele sebagai sumber omega 3 dan 6 dapat diketahui. Minyak ikan lele diekstraksi dengan metode sokletasi. Komposisi asam lemak dianalisis dengan kromatografi gas (GC-FID) yang sebelumnya diesterifikasi menggunakan BF3. Hasil penelitian menunjukkan bahwa komposisi asam lemak tak jenuh lebih banyak dibandingkan asam lemak jenuh. Ditemukan asam lemak omega 3 yang terdiri dari asam linolenat, asam eikosapentanoat (EPA) dan asam dokosaheksanoat (DHA) dan omega 6 yaitu asam linoleat. Perbandingan omega 3 dan omega 6 pada minyak ikan lele masih dalam rentang syarat perbandingan yang dianjurkan. Dilihat dari komposisi dan posisi asam lemak minyak ikan lele dimana mengandung asam lemak omega 3 dan omega 6 . Dengan demikian minyak ikan lele berpotensi sebagai sumber omega 3 dan 6 dari salah satu ikan air tawar yang banyak dikonsumsi masyarakat.
\end{abstract}

Kata kunci: asam lemak, omega 3 dan 6, ikan lele, esterifikai,GC-FID

\section{PENDAHULUAN}

Tingkat konsumsi ikan di Indonesia ratarata perkapita saat ini masih tergolong rendah yaitu $41 \mathrm{~kg} / \mathrm{tahun}$, kalah jauh dibandingkan Malaysia dan Singapura yang mencapai 70-80 kg/kapita/tahun dan Jepang yang mendekati $100 \mathrm{~kg} / \mathrm{kapita} /$ tahun (EIBN, 2017). Padahal ikan merupakan salah satu bahan pangan yang mengandung asam lemak yang kaya akan manfaat, karena mengandung sekitar $25 \%$ asam lemak jenuh dan $75 \%$ asam lemak tak jenuh. Asam lemak tak jenuh ganda (polyunsaturated fatty acid/PUFA) di dalamnya akan membantu proses tumbuh kembang otak (kecerdasan), serta perkembangan indra penglihatan dan sistem kekebalan tubuh bayi dan balita 
(Kainz M.J, et al, 2017). Asam-asam lemak alami yang termasuk asam lemak omega 3 adalah asam linolenat (C18:3, w-3), asam eikosapentanoat atau EPA (C20:5,w-3), asam dokosaheksanoat atau DHA (C22:6,w3 ), sedangkan untuk omega 6 adalah asam linoleat $(\mathrm{C} 18: 2, \mathrm{w}-6)$ dan asam arakhidonat atau ARA (C20:4, w-6). Adapun yang lebih dominan dalam minyak ikan adalah DHA, ARA dan EPA (Liu W, et al,2018).

Di Indonesia, ikan lele (Clarias sp.) merupakan salah satu komoditas budidaya ikan air tawar yang penting. Usaha budidaya ikan lele tergolong usaha perikanan yang tumbuh cepat dibandingkan dengan komoditas lainnya. Dalam kurun waktu 2009-2013, ikan lele merupakan komoditas ikan budidaya air tawar dengan peningkatan produksi terbesar yakni $88,98 \%$, di atas ikan gurame, ikan patin dan ikan mas. Dalam hal jumlah produksi pada tahun 2013, ikan lele menempati urutan ketiga terbesar di antara ikan budidaya air tawar dengan produksi sebesar 543.461 ton di bawah ikan nila sebesar 909.016 ton dan ikan bandeng sebesar 626.878 ton (Sayem A, et al, 2016).

Namun pada kenyataannya, pemanfaatan ikan lele budidaya air tawar yang melimpah belum dapat memberikan peranan yang signifikan, hal ini disebabkan karena kurangnya pengolahan ikan lele. Untuk meningkatkan potensi nilai jual ikan lele dapat dilakukan dengan pemanfaatan minyaknya sebagai sumber asam lemak esensial tak jenuh. Ada tidaknya EPA/DHA, jenis asam lemak lain dan posisi asam lemak tersebut pada triasilgliserol yang merupakan penyusun minyak ikan lele dapat diketahui dengan alat GC (Nurjanah, N, 2017).

\section{METODE PELAKSANAAN}

\section{Waktu dan Tempat}

Penelitian dilakukan di Laboratorium Pengolahan Pangan dan Pengolahan Hasil Pertanian, Program Studi Teknologi Hasil Pertanian, Fakultas Pertanian Universitas Katolik Santo Thomas Sumatera Utara, Medan. Pelaksanaan penelitian ini dilakukan pada bulan Juli 2018 hingga September 2018.

\section{Bahan}

Bahan yang digunakan adalah ikan lele yang diperoleh dari pasar Kota Medan. Reagensia untuk uji komposisi asam lemak adalah $\mathrm{NaOH} 0,5 \mathrm{~N}$, metanol, $\mathrm{BF}_{3}, \mathrm{NaCl}$ jenuh, $\mathrm{n}$ Heksan, dan $\mathrm{Na}_{2} \mathrm{SO}_{4}$ anhidrat. Bahan untuk uji fisiko-kimia diantaranya pelarut asam asetat-kloroform, KI jenuh, akuades, indikator pati $1 \%$, sodium tiosulfat $0,01 \mathrm{~N}, \mathrm{KOH} 0,5 \mathrm{~N}, \mathrm{HCl} 0,5 \mathrm{~N}$, indikator $\mathrm{pp}$, $\mathrm{KOH} 0,1 \mathrm{~N}$, etanol 95\%, kloroform, reagen iodium-bromida, KI $15 \%$, natrium tiosulfat $0,1 \mathrm{~N}$.

\begin{abstract}
Alat
Alat Instrumen yang digunakan adalah kromatografi gas (GC) Shimadzu QP 2010 ULTRA dengan detektor FID. Kolom yang digunakan adalah DB-23, panjang 30 meter, suhu kolom $40^{\circ}-250^{\circ} \mathrm{C}$, laju kenaikan suhu $20^{\circ} \mathrm{C}$ /menit, suhu detektor $260^{\circ} \mathrm{C}$, gas pembawa nitrogen, laju kolom 0,72 $\mathrm{ml} / \mathrm{menit}$, laju alir $37,7 \mathrm{ml} / \mathrm{menit}$ (Zhang $\mathrm{H}$, et al, 2018).
\end{abstract}

\section{RANCANGAN PENELITIAN}

Penelitian dilakukan dengan Rancangan Acak Lengkap (RAL) Rasio/perbandingan asam lemak omega 3 dan omega 6. Ekstraksi dilakukan dengan metode soxhletasi berdasarkan SNI. 01- 2354.3-2006. Sebanyak $500 \mathrm{~g}$ fillet daging ikan dicuci hingga bersih lalu digiling dan dikeringkan dalam oven vakum selama 3 jam pada suhu $70{ }^{\circ} \mathrm{C}$. Selanjutnya di ekstraksi selama \pm 50 menit pada suhu $\pm 80^{\circ} \mathrm{C}$ dengan pelarut n-heksan. Setelah itu ekstrak yang diperoleh didestilasi pada suhu $\pm 70{ }^{\circ} \mathrm{C}$ selama \pm 60 menit. Kemudian ekstrak yang telah didestilasi dioven pada suhu \pm $50{ }^{\circ} \mathrm{C}$ selama \pm 25 menit (Le H V, et al, 2019), Fatty acid profles of muscle, liver, heart and kidney of Australian prime lambs fed diferent polyunsaturated fatty acids enriched pellets in a feedlot system Scientific Reports (2019). Selanjutnya minyak ikan yang diperoleh dikarakterisasi sifat fisika kimia, 
dan komposisi asam lemak. Pengujian sifat fisika: titik keruh, total padatan. Pengujian sifat kimia: bilangan peroksida, bilangan penyabunan, kadar asam lemak bebas, bilangan iodium (AOAC, 2016).

Minyak ditimbang sebanyak $25 \mathrm{mg}$ di dalam tabung reaksi bertutup ditambahkan 1 ml larutan $\mathrm{NaOH} 0,5 \mathrm{~N}$ (dalam methanol), lalu dikocok selama 1 menit. Tabung ditutup rapat dan dipanaskan di dalam penangas air $100{ }^{\circ} \mathrm{C}$ selama 5 menit, kemudian didinginkan hingga suhu berkisar antara 30$40{ }^{\circ} \mathrm{C}$. Ditambahkan $1 \mathrm{ml} \mathrm{BF}_{3}$ dan tutup rapat kembali tabung, lalu dipanaskan di dalam penangas air $100{ }^{\circ} \mathrm{C}$ selama 5 menit. Kemudian didinginkan hingga suhu 30-40 ${ }^{\circ} \mathrm{C}$ lalu ditambahkan $1 \mathrm{ml}$ n-heksan dan dikocok kuat selama 30 detik. Ditambahkan $2 \mathrm{ml}$ larutan $\mathrm{NaCl}$ jenuh sehingga terbentuk dua lapisan yaitu air dan lapisan n-heksan. Lapisan n-heksan yang terbentuk dipisahkan sehingga yang tersisa hanya lapisan air.Lapisan air diekstraksi kembali dengan 1 $\mathrm{ml}$ n-heksan. Lapisan n-heksan yang terbentuk diambil dan disatukan dengan lapisan n-heksan yang pertama. Ekstrak nheksan ditambahkan $50 \mathrm{mg} \mathrm{Na} 2 \mathrm{SO}_{4}$ anhidrat dan biarkan selama 15 menit, selanjutnya dievaporasi. Fase cair bebas air diinjeksikan sebanyak $1 \mu$ untuk dianalisis dengan menggunakan alat kromatografi gas (Senarath S, et al, 2017. Diagram alir metode penelitian seperti pada Gambar 1.

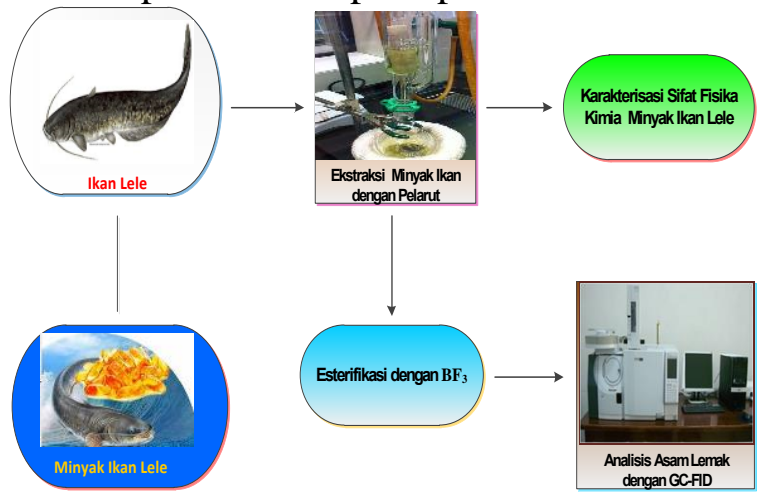

Gambar 1. Diagram alir metode penelitian

HASIL DAN PEMBAHASAN
Sifat fisika dan kimia minyak ikan lele dianalisis dengan penentuan titik keruh, total padatan bilangan peroksida, bilangan penyabunan, kadar asam lemak bebas, bilangan jodium disajikan pada Tabel 1 .

Tabel 1. Sifat fisika dan kimia minyak ikan lele

\begin{tabular}{llc}
\hline Karakteristik & Satuan & Jumlah \\
\hline Sifat Fisika & & \\
\hline Titik Keruh & ${ }^{\circ} \mathrm{C}$ & 65 \\
\hline Total Padatan & ${ }^{\circ}$ Brix & 28 \\
\hline Sifat Kimia & & \\
\hline Bilangan Peroksida & $\mathrm{meq} / \mathrm{kg}$ & 3,91 \\
\hline Bilangan Penyabunan & $\mathrm{mg} \mathrm{KOH} / \mathrm{g}$ & 105,75 \\
\hline Bilangan Iodium & $\mathrm{mg} / 100 \mathrm{~g}$ & 13,80 \\
\hline
\end{tabular}

Pengujian titik keruh dan total padatan ini dilakukan untuk mengetahui adanya pengotoran oleh bahan asing atau pencampuran minyak. Titik keruh ini ditetapkan dengan memanaskan minyak yang telah ditambahkan pelarut hingga jernih kemudian didiamkan hingga terbentuk kekeruhan. Temperatur pada waktu mulai terjadi kekeruhan disebut titik keruh. Dari nilai titik keruh dan total padatan menunjukkan minyak ikan lele masih belum murni. Tabel 1 memperlihatkan bahwa angka peroksida minyak ikan lele adalah $3,91 \mathrm{meq} / \mathrm{kg}$. Hal ini menunjukkan bahwa angka peroksida dari minyak ikan lele telah memenuhi persyaratan standar SNI 01-35551998 bilangan peroksida dalam minyak ikan maksimal 5,0 meq $/ \mathrm{kg}$ (BSN, 1998). Bilangan peroksida menunjukkan tingkat kerusakan dari minyak ikan, dimana semakin besar jumlah peroksida, menunjukkan makin besar pula derajat kerusakan pada minyak sehingga semakin rendah kualitas minyak ikan (Mason, $\mathrm{R}$, et al, 2017).

Bilangan penyabunan minyak ikan lele pada Tabel 1 adalah 105,75 mg KOH/g, menunjukkan lebih rendah dibandingkan standar (196-200 mg KOH/g). Rendahnya nilai penyabunan yang didapat menunjukkan bahwa terbentuknya asam lemak yang rantainya lebih panjang dalam minyak akan 
mempunyai berat molekul relatif besar dan mempunyai angka penyabunan yang kecil (Codex A.C, 2017).

Bilangan iodium menunjukkan seberapa banyak asam lemak tak jenuh yang terkandung didalam minyak ikan lele. Ikatan rangkap yang terdapat dalam asam lemak tak jenuh akan bereaksi dengan iodium. Bilangan iod yang tinggi menunjukkan bahwa minyak tersebut mengandung asam lemak tak jenuh yang banyak. Minyak yang mengandung banyak asam lemak tak jenuh, akan mengikat iod dalam jumlah yang besar. Dari Tabel 5 dapat dilihat bilangan iodium minyak ikan lele sebesar $13,80 \mathrm{mg} / 100 \mathrm{~g}$ yang menunjukkan lebih rendah dibandingkan standar bilangan iodium menurut SNI 01-3741-2002 yaitu sebesar 45 - 46 mg/100g [18]. Maka dapat disimpulkan bahwa bilangan iodium yang rendah menunjukkan bahwa minyak tersebut mengandung asam lemak tak jenuh yang rendah.

Analisis komposisi asam lemak menggunakan GC-FID melalui dua tahap yaitu pertama esterifikasi asam lemak menjadi metil ester asam lemak agar lebih mudah menjadi gas karena titik uap ester rendah. Setelah itu pemisahan asam lemak dalam GC-FID dan diperoleh kromatogram yang menunjukkan banyaknya senyawa yang terkandung dalam minyak. Kromatogram minyak ikan lele dapat dilihat pada Gambar 2, komposisi asam lemak yang terkandung dalam minyak ikan lele dapat dilihat pada Tabel 2.

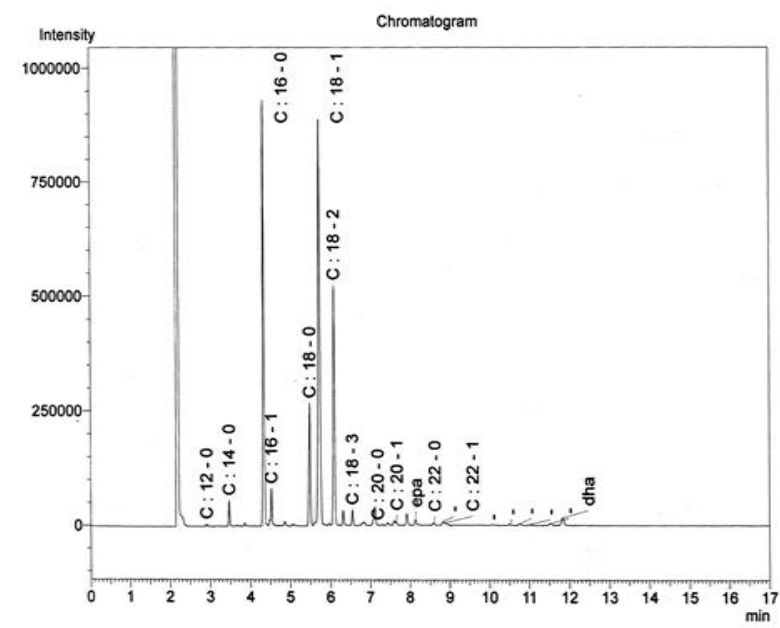

Gambar 2. Kromatogram minyak ikan lele

Berdasarkan Gambar 2 serta Tabel 2, diperoleh total asam lemak jenuh adalah $40,32 \%$, sedangkan total asam lemak tak jenuh adalah 59,65 \%. Kandungan asam lemak jenuh yang banyak terkandung adalah asam palmitat (C:16-0) sebesar 27,94\%. Asam lemak tak jenuh C:18-3 (asam linolenat), C:20-5 (EPA), C:22-6 (DHA) merupakan omega 3, asam lemak tak jenuh C:18-2 (asam linoleat) merupakan omega 6, dan asam lemak tak jenuh $\mathrm{C}: 18-1$ (asam oleat), C:20-1 (asam eikosenoat) merupakan omega 9.

Asam lemak omega 3 sebesar 2,48\% yang terdiri dari asam linolenat $0,99 \%$, EPA $0,48 \%$, DHA $1,01 \%$. Asam lemak omega 6 (asam linoleat) sebesar 17,07\%, dan asam lemak omega 9 sebesar $37,96 \%$ yang terdiri dari asam oleat $37,32 \%$ dan asam eikosenoat $0,64 \%$.

Tabel 2. Komposisi asam lemak yang terkandung dalam minyak ikan dengan gas chromatography

\begin{tabular}{|c|c|c|}
\hline Asam Lemak & & $\begin{array}{c}\text { Jumlah } \\
(\%)\end{array}$ \\
\hline \multicolumn{3}{|c|}{ Asam Lemak Jenuh (SFA) } \\
\hline Asam Miristat & $\mathrm{C}: 14-0$ & 1,41 \\
\hline Asam Palmitat & $C: 16-0$ & 27,94 \\
\hline Asam Stearat & C:18-0 & 9,07 \\
\hline Asam Arakidat & $\mathrm{C}: 20-0$ & 1,90 \\
\hline Asam Behenat & $C: 22-0$ & - \\
\hline$\Sigma$ SFA & & 40,32 \\
\hline \multicolumn{3}{|c|}{ Asam lemak tak jenuh tunggal (MUFA) } \\
\hline Asam Palmitoleat & C: $16-1$ & 1,88 \\
\hline Asam Oleat ${ }^{\text {W-9 }}$ & C: $18-1$ & 37,32 \\
\hline Asam Eikosenoat ${ }^{\text {W-9 }}$ & $C: 20-1$ & 0,64 \\
\hline
\end{tabular}




\begin{tabular}{ccc} 
Asam Erukat & C:22-1 & 0,26 \\
\hline$\Sigma$ MUFA & & 40,10 \\
\hline Asam lemak tak jenuh jamak (PUFA) & \\
Asam Linoleat & \\
As-6 & C:18-2 & 17,07 \\
Asam Linolenat $^{\mathrm{W}-3}$ & C:18-3 & 0,99 \\
Asam Eikosapentaenoat $^{\mathrm{W}-3}$ & C:20-5 & 0,48 \\
Asam Dokosaheksaenoat $^{\mathrm{W}-3}$ & $\mathrm{C}: 22-6$ & 1,01 \\
\hline$\Sigma$ PUFA & & 19,55 \\
\hline$\Sigma$ USFA (MUFA+PUFA) & & 59,65 \\
\hline
\end{tabular}

Berdasarkan data hasil GC dapat disimpulkan bahwa kandungan asam lemak omega 9 pada minyak ikan lele lebih tinggi dibandingkan omega 6 dan omega 3 . Hal ini sesuai dengan penyataan bahwa pada minyak ikan diketahui kandungan omega 9 lebih besar dibandingkan dengan omega 6 dan 3 (Demir D, et al, 2019).

Minyak ikan adalah salah satu zat gizi yang mengandung asam lemak kaya manfaat karena mengandung sekitar $25 \%$ asam lemak jenuh dan $75 \%$ asam lemak tak jenuh.
Salah satu metode yang dilakukan untuk menentukan nilai gizi suatu minyak atau lemak adalah berdasarkan komposisi asam lemaknya yaitu dengan menghitung persentasi penyimpangan dari perbandingan golongan asam lemak ideal dengan persentase SFA : MUFA : PUFA yaitu $33,33 \%: 33,33 \%: 33,33 \%$. Nilai gizi minyak ikan lele berdasarkan penyimpangan dari komposisi ideal dapat dilihat pada Tabel 3.

Tabel 3. Nilai gizi minyak ikan lele

\begin{tabular}{ccccc}
\hline \multicolumn{4}{c}{ Komposisi asam lemak (penyimpangan) } & $\begin{array}{c}\text { Penyimpangan } \\
(\%)\end{array}$ \\
\hline Sampel & $\begin{array}{c}\text { SFA } \\
(\%)\end{array}$ & $\begin{array}{c}\text { MUFA } \\
(\%)\end{array}$ & $\begin{array}{c}\text { PUFA } \\
(\%)\end{array}$ \\
\hline $\begin{array}{c}\text { Komposisi } \\
\text { ideal }\end{array}$ & $33,33(0,00)$ & $33,33(0,00)$ & $33,33(0,00)$ & 0,00 \\
$\begin{array}{c}\text { Minyak } \\
\text { ikan lele }\end{array}$ & $40,32(6,99)$ & $40,10(6,77)$ & $19,55(13,78)$ & 27,54 \\
\hline
\end{tabular}

Berdasarkan Tabel 3 komposisi asam lemak pada minyak ikan lele terdiri dari asam lemak jenuh (SFA) sebesar 40,32\%, asam lemak tak jenuh tunggal (MUFA) $40,10 \%$, dan asam lemak tak jenuh jamak (PUFA) 19,55\%. Dibandingkan dengan kompsisi ideal minyak ikan didapat total penyimpangan $27,54 \%$, data ini menyatakan bahwa nilai gizi minyak ikan lele belum memenuhi komposisi ideal, dimana perbandingan ketiga jenis asam lemak belum memenuhi perbandingan 33,33\% dan total penyimpangan sangat tinggi. Tetapi secara keseluruhan minyak ikan lele sudah memenuhi komposisi SFA, MUFA dan PUFA yang bernilai gizi yang baik. Dimana total asam lemak tak jenuh MUFA dan UFA lebih tinggi dibandingkan asam lemak jenuh.
Perbandingan asam lemak omega 3 dan omega 6 dari minyak ikan lele yang diperoleh dari analisis dengan kromatografi gas dapat dilihat pada Tabel 4 .

Tabel 4. Rasio/perbandingan asam lemak omega 3 dan omega 6

\begin{tabular}{cccc}
\hline Sampel & $\begin{array}{c}\Sigma \\
\text { Omega } \\
3\end{array}$ & $\begin{array}{c}\Sigma \\
\text { Omega } \\
6\end{array}$ & $\begin{array}{c}\text { Perbandi } \\
\text { ngan } \\
(\dot{\omega}-3 / \omega-6)\end{array}$ \\
\hline $\begin{array}{c}\text { Minyak Ikan } \\
\text { Lele }\end{array}$ & $2,48 \%$ & $17,07 \%$ & $(1: 7)$ \\
\hline
\end{tabular}

Berdasarkan Tabel 4 didapat rasio/perbandingan omega 3 dan omega 6 pada minyak ikan lele yaitu (1:7). Untuk mempertahankan status asam lemak tak jenuh rantai panjang yang sehat dianjurkan perbandingan antara omega 3 dan omega 6 
yaitu (1:1) atau setidaknya (2:1) yang merupakan perbandingan optimal (Akerele $\mathrm{O}$ A and Cheema S K, 2016) Asupan yang berlebihan dari omega 3 dapat menimbulkan efek yang tidak baik terhadap aktivitas enzimatik dan efek terhadap permeabilitas membran. Asupan omega 6 yang berlebihan jika melebihi perbandingan ( (20:1) dapat memicu patogenesis dari inflammasi, meningkatkan resiko terkena kanker, kerusakan penglihatan, autoimun juga penyakit neurodegeneratif. Rasio/perbandingan omega 3 dan omega 6 pada minyak ikan lele masih dalam rentang syarat perbandingan sehingga masih memenuhi persyaratan (Alagawany $\mathrm{M}$, et al, 2019)

\section{KESIMPULAN}

Komposisi asam lemak dari minyak ikan lele sebagai berikut: SFA sebanyak 40,32\%, MUFA sebanyak 40,10\%, PUFA sebanyak 19,55\%. Asam lemak omega 3 sebesar $2,48 \%$ yang terdiri dari asam linolenat $0,99 \%$, EPA $0,48 \%$, DHA $1,01 \%$, dan omega 6 (asam linoleat) sebesar 17,07\%. Rasio/perbandingan omega 3 dan omega 6 pada minyak ikan lele masih dalam rentang syarat perbandingan yang dianjurkan sehingga masih memenuhi persyaratan. Dilihat dari kandungan asam lemak minyak ikan lele mengandung asam lemak omega 3 dan omega 6 dengan perbandingan dalam batas yang dianjurkan, sehingga sangat baik dikomsumsi untuk meningkatkan kesehatan manusia.

\section{UCAPAN TERIMA KASIH}

Penulis menyampaikan ucapan terimakasih kepada Rektor Universitas Katolik Santo Thomas, Rektor Universitas Sumatera Utara dan Kementerian Ristekdikti RI untuk ijin tugas belajar dan bantuan dana pendidikan dan penelitian BPPDN di program Doktor Ilmu Kimia Universitas Sumatera Utara.

\section{DAFTAR PUSTAKA}

Akerele O A and Cheema S K 2016 A balance of omega-3 and omega- 6 polyunsaturated fatty acids is important in pregnancy Journal of Nutrition \& Intermediary Metabolism 5 (2016) 23-33.

Alagawany M, Elnesr S E, Farag M R, ElHack M E A, Khafaga A F, Taha A E, Tiwari R, Yatoo M I, Bhatt P, Khurana S K and K. Dhama, 2019, Omega-3 and Omega-6 Fatty Acids in Poultry Nutrition: Effect on Production Performance and Health, Animals 2019,9,573; doi:10.3390/ani9080573.

Alfieri A, Imperlini E, Nigro E, Vitucci D, Orrù $\mathrm{S}$, Daniele $\mathrm{A}$, Buono $\mathrm{P}$ and Mancini A 2018 Effects of plant oil interesterified triacylglycerols on lipemia and human health. Int. J. Mol. Sci.19,104.

Association of Official Analytical Chemists 2016 Official Methods of Analysis of AOAC International 20th Edition Rockville, MD 20850-3250 USA.

Badan Standardisasi Nasional, 1998, SNI 01-3555-1998, Cara Uji Minyak dan Lemak, Badan Standarisasi Nasional RI, Jakarta.

Badan Standardisasi Nasional, 2002, SNI 01-3741-2002, Minyak Goreng, Badan Standarisasi Nasional RI, Jakarta.

Codex Alimentarius Commission 2017 Standard for Fish Oil CXS 329-2017 Food and Agriculture Organization of the United Nations WHO Roma Italy.

Demir D and S. Sarogöz, 2019, The Effects of Different Feeding Times and Diets On The Whole Body Fatty Acid Composition of Goldfish (Carassius auratus) larvae Food Sci. Technol, 
Campinas, 39(1): 216-223, Jan.-Mar. 2019.

Effiong, Mmandu U, Akpan and Anthony W 2016 Evaluation of the Biochemical Responses of Catfish (Clarias gariepinus Burchell, 1822) after Replacing Fish Oil with Plant-based Oils in their Diets J. Appl. Sci. Environ. Manage. Dec. 2016 Vol. 20 (4) $1069-1073$.

EIBN 2017 Fisheries and aquaculture Europe Indonesia business network sector report www.eibn.org.

Ivanovs K and Blumberga D 2017 Extraction of fish oil using green extraction methods: a short review Energy Procedia 128 (2017) 477-483.

Kainz M J, Hager H H, Rasconi S, Kahilainen K K, Amundsen P A and Hayden B 2017 Polyunsaturated fatty acids in fishes increase with total lipids irrespective of feeding sources and trophic position, Ecosphere volume 8 (4) April 2017.

Le H V, Nguyen D V, Nguyen Q V, MalauAduli B S, Nichols P D and A.E.O. Malau-Aduli, 2019, Fatty acid profles of muscle, liver, heart and kidney of Australian prime lambs fed diferent polyunsaturated fatty acids enriched pellets in a feedlot system Scientific Reports (2019) 9:1238.

Liu W, Xie X, Liu M, Zhang J, Liang W and Chen X 2018 Serum $\omega$-3 polyunsaturated fatty acids and potential infuence factors in elderly. patients with multiple cardiovascular risk factors, Scientific Reports 8:1102.

Mason R. P. and S. C.R. Sherratt, 2017, Omega-3 Fatty Acid Fish Oil Dietary Supplements Contain Saturated Fats and Oxidized Lipids That May Interfere with Their Intended
Biological Benefits, Biochemical and Biophysical Research Communications 483 (2017) 425-429

Nurjanah N, Nurilmala M, Hidayat T and Azri R Y I 2016 Fatty Acid Composition and Cholesterol Indian Mackerel (Rastrelliger kanagurta) Due Frying Process, International Journal of Materials Chemistry and Physics Vol. 2, No. 2, 2016, pp. 54-61.

Peltoma E, Johnson M D and Taipale S J 2018 Marine cryptophytes are great sources of EPA and DHA Marine Drugs 16, 3: 1-11.

Pereira F. E. X. G., F. d. C. Medeiros, H. A. L. Rocha and K. S. da Silva, 2019, Effects of Omega-6/3 and Omega-9/6 Nutraceuticals on Pain and Fertility in Peritoneal Endometriosis in Rats, Acta Cir Bras. 2019;34 (4):e201900405.

Sayem A, Habib A and Sarkar P 2016 Extraction and identification of PUFA from African Catfish (Clarias gariepinus) Skin, International Journal of Fisheries and Aquatic Studies 4(4): 312-314.

Senarath S, Yoshinaga K, Nagai T, Yoshida A, Beppu F, Jayasinghe C, Devadawson C and Gotoh N 2017 Quantitative analysis of the distribution of cis-eicosenoic acid positional isomers in marine fishes from the indian ocean J. Oleo Sci. 66, (2) 187-197.

Simopoulos A P 2016 An increase in the omega-6/omega-3 fatty acid ratio increases the risk for obesity Nutrients 8, 128: 1-17.

Zárate.R, Jaber-Vazdekis N, Tejera N, Pérez J A, and Rodríguez C 2017. Significance of long chain polyunsaturated fatty acids in human health, Clin Transl Med. 2017; 6: 25. 
Zhang H, Shen Y, Zhang Y, Li L and Wang X 2018 Regiospecific analysis of fatty acids and calculation of triglyceride molecular species in marine fish oils, BioMed Research International Volume 2018, Article ID 9016840. 